\title{
Trends in Prevalence and Prognosis in Subjects With Acute Chronic Respiratory Failure Treated With Noninvasive and/or Invasive Ventilation
}

Arnaud Gacouin MD, Stephane Jouneau MD PhD, Julien Letheulle MD, Mallory Kerjouan MD,
Pierre Bouju MD, Pierre Fillatre MD, Yves Le Tulzo MD PhD, and Jean Marc Tadié MD PhD

BACKGROUND: The pattern and outcome of noninvasive ventilation (NIV) use in patients with acute or chronic respiratory disease other than COPD is not well known. The aims of this study were to investigate trends over time in underlying respiratory diseases, use of NIV, and outcomes in COPD and non-COPD patients with acute respiratory failure. METHODS: We made a retrospective analysis of data recorded prospectively from 1,113 subjects admitted between 1998 and 2012. RESULTS: Subject diagnoses were distributed as follows: COPD, $n=568(51 \%)$; bilateral bronchiectasis, $n=113(10 \%)$; obesity, $n=166(15 \%)$; chronic diffuse interstitial lung disease, $n=131(12 \%)$; restrictive pulmonary disease, $n=113(10 \%)$; and asthma, $n=22(2 \%)$. The proportion of subjects with bilateral bronchiectasis significantly decreased (OR $0.91,95 \%$ CI 0.865 $0.951, P<.001)$, whereas the proportion of subjects with obesity increased (OR 1.03, 95\% CI $1.001-1.063, P=.049)$ over time. The use of NIV (OR 1.05, 95\% CI 1.010-1.090, $P=.01$ ) and the proportion of subjects initially treated with NIV (OR 1.05, 95\% CI 1.013-1.094, $P=.009)$ increased significantly in COPD subjects only. Time trend of mortality was not significant (OR $0.98,95 \%$ CI $0.95-1.01, P=.23$ ), whereas the severity of illness in subjects significantly increased. Transition from NIV to invasive mechanical ventilation (IMV) (OR 2.05, 95\% CI 1.36-3.11, $P=<.001$ ), IMV (OR 10.49, 95\% CI 4.88-10.56, $P<.001)$ and diffuse interstitial lung disease (OR 10.63, 95\% CI $5.43-20.83, P<.001$ ) were independently associated with death in the ICU. CONCLUSIONS: Over time, respiratory diseases have changed in non-COPD subjects and trends in the use and efficacy of NIV differ between COPD and non-COPD subjects. Mortality remained stable while the severity of illness in subjects increased. In COPD and non-COPD subjects, transition from NIV to IMV was associated with a poorer prognosis. Key words: noninvasive ventilation; chronic obstructive pulmonary disease; bronchiectasis; interstitial lung disease; acute respiratory failure; mechanical ventilation; epidemiology; mortality. [Respir Care 2015;60(2):210-218. (C) 2015 Daedalus Enterprises]

\section{Introduction}

Acute respiratory failure (ARF) in chronic respiratory disease remains a major reason for mechanical ventilation

Drs Gacouin, Letheulle, Bouju, Fillatre, Le Tulzo, and Tadié are affiliated with the Centre Hospitalier Universitaire Rennes, Maladies Infectieuses et Réanimation Médicale; Drs Gacouin, Letheulle, Kerjouan, Bouju, Fillatre, Le Tulzo, and Tadié are affiliated with Université Rennes I, Faculté de Médecine, Biosit; Drs Gacouin, Le Tulzo, and Tadié are affiliated with Institut National de la Santé et de la Recherche Médicale CIC-0203, Faculté de Médecine, Université Rennes I, Institut Formation Recherche 40; Drs Jouneau and Kerjouan are affiliated with the Centre Hospitalier Universitaire Rennes, Service de Pneumologie; and Dr Jou-
(MV) in ICU patients. Noninvasive ventilation (NIV) as first-line supportive therapy may be used. The use of NIV to treat exacerbation of COPD is supported by results of randomized studies and therefore recommended. ${ }^{1-4}$ However, in clinical practice, NIV is used beyond guideline recommendations, ${ }^{5}$ and despite concerns about the effi-

\footnotetext{
neau is affiliated with Institut de Recherche en Santé, Environnement et Travail 1085, Faculté de Pharmacie, Rennes, France.

Dr Gacouin presented a portion of this research at the 42nd Annual Congress of the Société de Réanimation de Langue Française, held January 15-17, 2014, in Paris, France.
} 
cacy of NIV as supportive therapy in ARF in patients with preexisting conditions other than COPD, NIV is broadly considered as the first line of respiratory support in patients with bronchiectasis, ${ }^{6,7}$ rib cage or parenchymal restrictive diseases, ${ }^{8-10}$ obesity, ${ }^{11}$ or asthma. ${ }^{12,13}$ Studies showed that, over the period 1998-2008, NIV was increasingly used in patients suffering from COPD. ${ }^{14,15}$ Schnell et al ${ }^{16}$ showed recently, in a multi-center database study of subjects who required ventilatory support for ARF between 1997 and 2011, that use of NIV improved outcomes in subjects with acute or chronic respiratory failure. In the large surveys assessing the use of NIV in critically ill patients, ${ }^{16-18}$ COPD and non-COPD patients are generally not distinguished among those with ARF. There is a need to assess NIV use in non-COPD patients over a period of several years similarly to that performed in COPD patients.

The aims of this retrospective study performed on data collected prospectively over a 15 -y period in an unselected population with ARF and chronic respiratory disease were to investigate temporal trends in respiratory diseases involved and to assess trends in NIV use and outcomes in COPD and non-COPD patients.

\section{Methods}

\section{Inclusion and Exclusion Criteria}

Subjects were identified through our institutional computerized database. The study was approved by the hospital ethics committee (13-73). We included all patients aged $>18$ y admitted between January 1, 1998 and December 31,2012, for ARF treated with NIV and/or invasive mechanical ventilation (IMV) initiated in the ICU or in the emergency department, and suffering from one of the following chronic respiratory diseases: COPD, bilateral bronchiectasis, obesity, restrictive disease, diffuse interstitial lung disease (ILD), and asthma. When NIV or IMV was initiated in the emergency department, subjects were managed by ICU physicians and transferred quickly to the ICU. Patients with cystic fibrosis, patients with restrictive syndrome secondary to neuromuscular disease, postoperative patients, and patients who were ventilated for reason other than respiratory failure, such as stroke or

The authors have disclosed no conflicts of interest.

Correspondence: Arnaud Gacouin MD, Service des Maladies Infectieuses et Réanimation Médicale, Centre Hospitalier Universitaire Rennes, F-35033 Rennes, France. E-mail: arnaud.gacouin@chu-rennes.fr.

DOI: $10.4187 /$ respcare. 03467

\section{QUICK LOOK}

\section{Current knowledge}

Noninvasive ventilation (NIV) is the standard of care for exacerbations of COPD, decreasing the incidence of intubation and mortality. The use of NIV in other disease states has met with varying degrees of success and has not achieved the same level of evidence.

\section{What this paper contributes to our knowledge}

Over a 14-y study period, the use of NIV in subjects with COPD increased, while severity of illness increased and mortality remained constant. Failure of NIV and the need for intubation in all subject groups was independently associated with death in the ICU.

septic shock not due to pneumonia, were not included in the study.

\section{Definitions}

COPD was diagnosed according to the clinical and radiological criteria defined by the American Thoracic Society. ${ }^{19}$ For bilateral bronchiectasis, medical records were reviewed to ensure that cough and sputum productions were reported by subjects for at least $5 \mathrm{y}$ before the admission to ICU and that bilateral dilated and thickened airways were visible on the chest $\mathrm{x}$-rays performed just before ICU admission and/or on those performed at the admission on ICU and confirmed by a high-resolution computed tomography scan performed before ICU admission. Obesity was considered in subjects with body mass index $>30 \mathrm{~kg} / \mathrm{m}^{2}$ and was defined as morbid when body mass index $>40 \mathrm{~kg} / \mathrm{m}^{2}$. Chronic restrictive pulmonary disease included deformations of the rib cage due to kyphoscoliosis and post-tuberculosis sequelae including extended calcifications of the pleura as previously defined. ${ }^{10} \mathrm{Re}-$ garding chronic diffuse ILD, the disease was considered chronic when diagnosed at least 6 months before admission to the ICU, and diffuse parenchymal lung disease was confirmed on high-resolution computed tomography scan. Based on the consensus classification of the idiopathic interstitial pneumonias, ${ }^{20}$ the following clinical conditions were distinguished: idiopathic pulmonary fibrosis (IPF) and non-IPF ILD including collagen vascular diseases, stage IV sarcoidosis, pneumoconiosis, chronic hypersensitivity pneumonitis, and drug-induced ILD. Severe acute asthma was defined according to the usual criteria. ${ }^{21}$ Nocturnal hypoventilation was previously documented by sleep polysomnography.

Morbid obesity was always considered as a primary etiology of chronic respiratory disease. In obese subjects 
without morbid obesity, respiratory failure was considered as secondary to obesity if no other identified cause for respiratory failure was found. Consequently, for non-morbidly obese subjects suffering from COPD, COPD was the primary diagnosis. Type of respiratory support was considered for the entire ICU stay, and subjects were classified as treated with NIV only, treated with IMV only, or transitioned from NIV to IMV.

\section{Noninvasive Ventilation}

Our ICU is a mixed 21-bed ICU in a university hospital that admits $\sim 1,000$ patients/year, mostly for medical conditions. NIV has been used in our ICU since 1990. No other facilities existed for the acute management of either groups of these patients outside the ICU until 2010. From 2010 onward, NIV could also be initiated in the emergency department. The usual criteria used in our ICU for admission were those used for the diagnosis of respiratory failure. The nurse-to-patient ratio increased from 1 to 3.5 to 1 to 2.5 in November 2010. Subjects were treated with ventilators that were not able to compensate for air leaks (Servo C and Servo 300 respirators, Siemens, Sölna, Sweden) until June 01, 2000. Thereafter, ventilators able to compensate for air leaks were used (Servo-i, Siemens; or Evita XL, Dräger, Telford, Pennsylvania). The decision to initiate NIV was made by the subject's attending physician according to the usual criteria used in our ICU, that is, neurologic signs of hypercapnia, signs of acute respiratory distress (dyspnea increased over usual, accessory muscle use, tachypnea, paradoxical breathing), and gas exchange abnormalities $\left(\mathrm{S}_{\mathrm{aO}_{2}}<90 \%, \mathrm{P}_{\mathrm{aCO}_{2}}>45 \mathrm{~mm} \mathrm{Hg}, \mathrm{pH}<7.35\right)$.

At NIV initiation, our main concern was to maximize the subject's compliance with therapy. For that, pressure support ventilation was started with low inspiratory pressure and gradually titrated upward as tolerated by the subjects. $\mathrm{F}_{\mathrm{IO}_{2}}$ was set to obtain a $\mathrm{S}_{\mathrm{pO}_{2}}$ of $90 \%$ or more, and PEEP was applied in case and control groups (typically $3-6 \mathrm{~cm} \mathrm{H}_{2} \mathrm{O}$ ). The intubation decision was made by subject's attending physician, on the basis of respiratory or cardiac arrest, agitation or altered consciousness, ineffective cough, pneumothorax, or hemodynamic instability. In addition to these criteria, NIV failure was considered when ventilation was ineffective because of major air leaks, or in subjects whose respiratory state worsened under NIV. From 2011, NIV was considered for difficult-to-wean subjects to reduce the duration of IMV. Immediate NIV following extubation was applied in subjects who had increased $\mathrm{P}_{\mathrm{aCO}}$ during the spontaneous breathing trial but who did not develop clinical signs of poor tolerance.

\section{Data Collection}

The following variables recorded on ICU admission were collected: age, sex, body mass index, prior treatment with corticosteroids, prior home oxygen therapy, prior diagnosis of sleep apnea syndrome, associated cardiac comorbidity for which subjects received treatment excepting hypertension, lung and/or upper airway cancer recently diagnosed or currently treated, $\mathrm{P}_{\mathrm{aCO}}$ values before initiation of $\mathrm{MV}$ (recorded as $\geq 50 \mathrm{~mm} \mathrm{Hg}$ ), and the Simplified Acute Physiology Score (SAPS) II calculated within $24 \mathrm{~h}$ after admission. When diagnosed at admission, the following suspected causative factors for exacerbation of the disease leading to respiratory failure were noted: bronchitis or pneumonia, pneumothorax, and pulmonary embolism; these were then regrouped as precipitating factors. In addition, the following outcome variables were recorded: treatment with NIV, treatment with IMV, or treatment with corticosteroids. Only the first episode of ventilatory support for each subject was included. Regarding ICU outcomes, in addition to mortality, we recorded the duration of MV, the length of the ICU stay, and the proportion of subjects with ICU-acquired pneumonia, as previously defined. ${ }^{22}$

\section{Data Analysis}

Qualitative or categorical variables were expressed as number and percentages and continuous variables as mean $\pm \mathrm{SD}$. We first examined temporal trends for changes in the frequency of COPD, bilateral bronchiectasis, ILD, obesity, restrictive disease, and asthma; second, we examined temporal trends for changes in NIV and IMV use and in mortality from 1998 to 2012 using the logistic regression analysis with time as covariate. Temporal trends in SAPS II scores, durations of MV, and ICU lengths of stay were assessed by linear regression. Then, subjects were compared as to whether they received NIV only, IMV only or whether they failed NIV. Finally, we examined 2 outcomes: acquisition of ventilator-associated pneumonia and in-ICU mortality. The data were compared using the chisquare test or Fisher's exact test for categorical variables and using a one-way analysis of variance test for continuous variables. Regarding multivariate analysis for mortality, variables with $P \leq 0.10$ were entered into a logistic regression model. The results were expressed in terms of the odds ratio (OR) with corresponding 95\% CI. Tests were 2-tailed, and a value of $P<.05$ was considered significant.

\section{Results}

\section{Characteristics of the Subjects}

A total of 1,113 subjects were included in the cohort. General characteristics are listed in Table 1 . Obesity was present in 314 subjects (28\%). Among the 166 subjects with respiratory failure due to obesity, obesity was morbid in 114 sub- 
Table 1. Comparisons Between Subjects Treated With NIV, Subjects Treated With IMV, and Subjects Who Failed NIV

\begin{tabular}{|c|c|c|c|c|c|}
\hline & $\begin{array}{c}\text { Whole } \\
\text { Population } \\
(N=1,113)\end{array}$ & $\begin{array}{c}\text { NIV } \\
\text { Success } \\
(n=423)\end{array}$ & $\begin{array}{c}\text { IMV } \\
(n=452)\end{array}$ & $\begin{array}{c}\text { NIV } \\
\text { Failure } \\
(n=238)\end{array}$ & $P$ \\
\hline COPD, $n(\%)$ & $568(51)$ & $233(55)$ & $232(51)$ & $103(43)^{*}$ & .01 \\
\hline Bilateral bronchiectasis, $n(\%)$ & $113(10)$ & $40(9)$ & $45(10)$ & $28(12)$ & .63 \\
\hline Obesity (BMI > 30), $n(\%)$ & $166(15)$ & $88(21)$ & $46(10)$ & $32(13)$ & $<.001$ \\
\hline Diffuse interstitial pneumonia, $n(\%)$ & $131(12)$ & $21(5)$ & $68(15)$ & $42(18)^{*}$ & $<.001$ \\
\hline Restrictive disease, $n(\%)$ & $113(10)$ & $41(10)$ & $40(9)$ & $32(13)$ & .15 \\
\hline Asthma, $n(\%)$ & $22(2)$ & $0(0)$ & $21(5)$ & $1(0.5)$ & $<.001$ \\
\hline Male gender, $n(\%)$ & $686(62)$ & $243(57)$ & $290(64)$ & $153(64)$ & .08 \\
\hline SAPS II points $($ mean \pm SD) & $42 \pm 16$ & $34 \pm 10$ & $48 \pm 17$ & $46 \pm 15$ & $<.001$ \\
\hline Age, y (mean $\pm \mathrm{SD})$ & $67 \pm 14$ & $68 \pm 12$ & $66 \pm 13$ & $67 \pm 12$ & .10 \\
\hline $\mathrm{P}_{\mathrm{aCO}_{2}}>50 \mathrm{~mm} \mathrm{Hg}$ before ventilation, $n(\%)$ & $835(75)$ & $349(82)$ & $308(68)$ & $178(75) \dagger$ & $<.001$ \\
\hline Obstructive sleep apnea syndrome, $n(\%)$ & $90(8)$ & $48(11)$ & $25(6)$ & $17(7)$ & .006 \\
\hline Prior oxygen therapy, $n(\%)$ & $224(20)$ & $100(24)$ & $72(16)$ & $52(22)$ & .01 \\
\hline Lung and/or upper airway cancer, $n(\%)$ & $57(5)$ & $11(3)$ & $34(8)$ & $12(5)$ & .004 \\
\hline Chronic heart disease, $n(\%)$ & $402(36)$ & $147(35)$ & $168(37)$ & $87(37)$ & .58 \\
\hline Morbid obesity (BMI > 40), $n(\%)$ & $114(10)$ & $65(15)$ & $20(4)$ & $29(12)$ & $<.001$ \\
\hline Infection or pneumothorax or pulmonary embolism, $n(\%)$ & $385(36)$ & $117(28)$ & $181(40)$ & $87(37) \dagger$ & $<.001$ \\
\hline Steroids $\geq 1 \mathrm{mg} / \mathrm{kg} / \mathrm{d}, n(\%)$ & $656(59)$ & $191(45)$ & $309(68)$ & $156(66)^{*}$ & $<.001$ \\
\hline $\begin{array}{l}* \text { NIV success vs NIV failure, } P<.01 . \\
\dagger \text { NIV success vs NIV failure, } P<.05 . \\
\text { NIV = noninvasive ventilation } \\
\text { IMV = invasive mechanical ventilation } \\
\text { SAPS = Simplified Acute Physiologic Score } \\
\text { BMI = body mass index }\end{array}$ & & & & & \\
\hline
\end{tabular}

jects $(10 \%)$ and no reason other than obesity was identified in 52 other obese subjects. Obesity was present as coexisting disease in 148 subjects (13\%). Nocturnal hypoventilation was diagnosed in 71 obese subjects only. Among the 131 subjects with ILD, IPF was diagnosed in 40 subjects and non-IPF ILD in 91 subjects (stage IV sarcoidosis, $n=2$; collagen vascular diseases, $n=20$; drug-induced ILD, $n=46$; pneumoconiosis, $n=9$; hypersensitivity pneumonitis, $n=2$ ). At admission to the ICU, bronchitis or pneumonia was diagnosed in 256 patients (34\%), pulmonary embolisms in 25 patients $(2 \%)$, and pneumothorax in 19 subjects (2\%). Over the study period, SAPS II increased significantly in COPD subjects $(P=.04)$, in patients with bilateral bronchiectasis $(P=.0047)$, in obese subjects $(P=.003)$, and in subjects with restrictive disease $(P=.049)$ but not in subjects with ILD $(P=.60)$ or asthma $(P=.52)$. The duration of MV decreased significantly in COPD patients only $(P<.001)$. In 2012, mean duration of IMV and NIV in COPD patients decreased significantly compared with $1998(7 \pm 4 \mathrm{~d}$ vs $19 \pm 18 \mathrm{~d}, P=.009$ and $5.5 \pm 3 \mathrm{~d}$ vs $3 \pm 2 \mathrm{~d}, P=.002$, respectively).

\section{Trends in the Distribution of COPD and Non-COPD Subjects}

Trend analysis showed that, during the study period, the proportion of subjects with bilateral bronchiectasis dimin- ished significantly (OR $0.91,95 \%$ CI $0.865-0.951$, $P<.001$ ), whereas the proportion of subjects with obesity as main reason for respiratory disease increased significantly (OR 1.03, 95\% CI 1.001-1.063, $P=.049$ ) (Fig. 1). No significant trend over time was noted in the other subjects, and results for trends were: COPD subjects (OR $1.02,95 \%$ CI $0.990-1.046, P=.20)$, subjects with diffuse ILD (OR 1.01, 95\% CI $0.968-1.053, P=.57$ ), subjects with restrictive disease (OR $0.98,95 \%$ CI $0.939-1.028$, $P=.43$ ), and subjects with asthma (OR 1.06, 95\% CI $0.960-1.068, P=.25)$.

\section{Trends in NIV Use}

Among the 568 COPD subjects, 233 (41\%) were treated with NIV only. In non-COPD subjects, proportions of subjects treated with NIV only were as follows: 40 of 113 subjects with bronchiectasis (35\%), 41 of 113 with restrictive disease (35\%), 21 of 131 with ILD (16\%), 152 of 304 with obesity $(50 \%)$, and none with asthma. Trends in NIV use, first-line treatment with NIV, and NIV failure in COPD and non-COPD subjects are reported in Figure 2. NIV use increased significantly when the trend was analyzed for the entire population (OR 1.03, 95\% CI 1.004-1.058, $P=.04)$. However, after subgroup analysis on each of the chronic respiratory diseases, it appeared that the use of NIV (OR 1.05, 95\% CI 1.010-1.090, $P=.01$ ) and the 


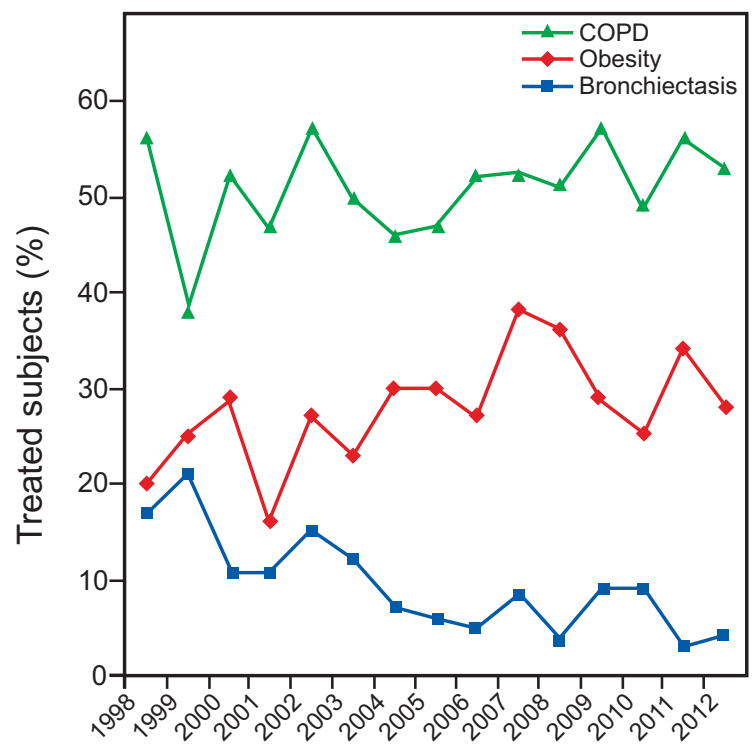

Fig. 1. Trends in COPD subjects, subjects with bilateral bronchiectasis, and subjects with respiratory failure due to obesity over the study period.

proportion of subjects initially treated with NIV (OR 1.05, 95\% CI 1.013-1.094, $P=.009$ ) increased significantly in COPD subjects only. The proportion of COPD subjects (OR 0.98, 95\% CI 0.939-1.030, $P=.48$ ) and non-COPD patients (OR $>0.99,95 \%$ CI $0.956-1.044, P=.97)$. After comparisons, the proportion of subjects who failed NIV was not significantly higher before June 1, 2000 when patients were ventilated with ventilators not able to compensate for air leaks than after June 1, 2000 (61 subjects on 163 subjects receiving initial NIV [37\%] vs 175 subjects on 496 receiving initial NIV [35\%], respectively, $P=.65$ ). Comparisons of characteristics in subjects who received NIV only, IMV only, or failed NIV are shown in Table 1. Age did not vary significantly between groups and did not increase significantly over the study period.

\section{ICU-Acquired Pneumonia}

One hundred and eleven subjects (10\%) had ventilatorassociated pneumonia during their ICU stay. Over the study period, the proportion of subjects with ventilator-associated pneumonia trended to diminish significantly in COPD patients only (OR $0.93,95 \%$ CI $0.869-0.993, P=.03$ ). Subjects who acquired ventilator-associated pneumonia differed significantly from those who did not for SAPS II score, treatment with steroids, treatment with NIV, NIV failure, and duration of MV (data not shown). Use of NIV was independently associated with a lower risk to acquire pneumonia in the ICU in COPD patients only (OR 0.41, $95 \%$ CI $0.05-0.31, P=.002$ ).
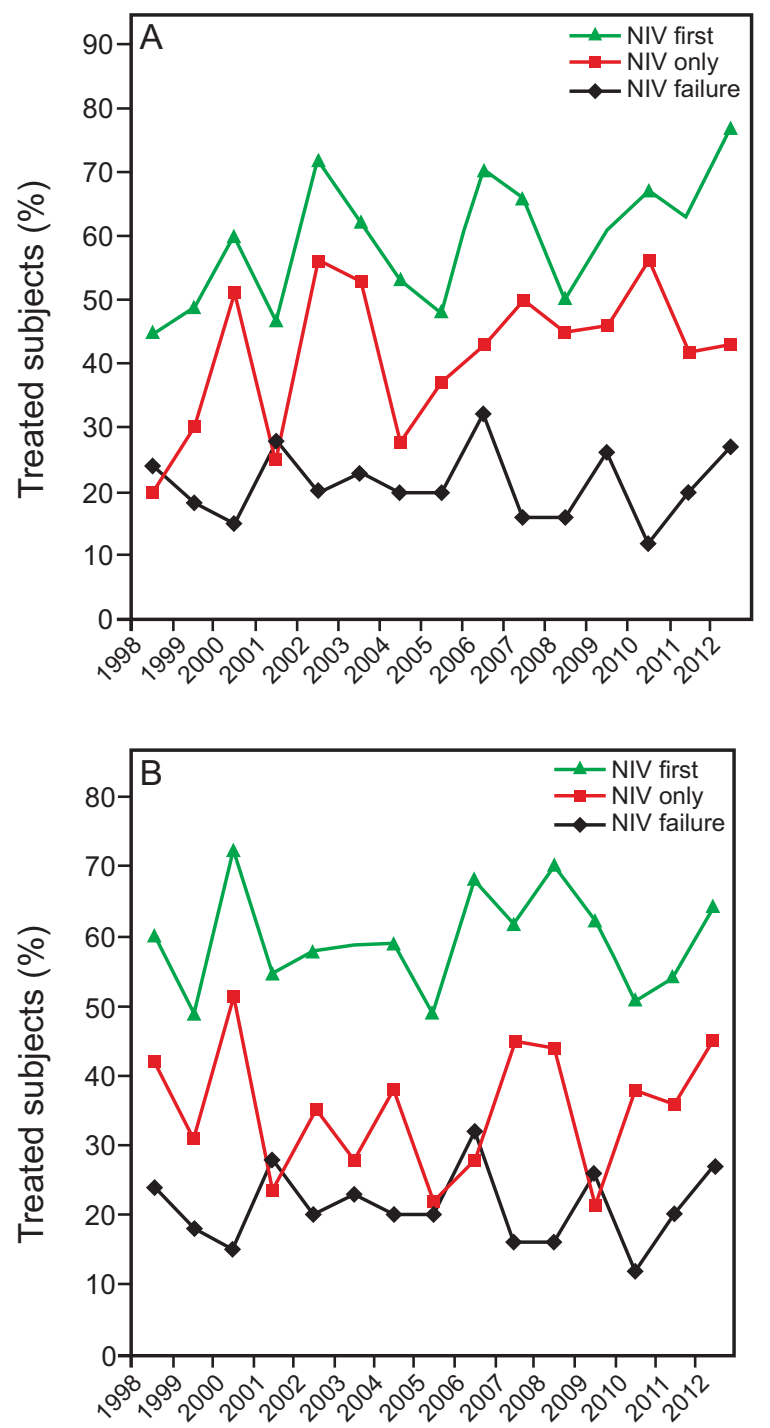

Fig. 2. Trends in subjects treated with noninvasive ventilation (NIV) only, in subjects who received NIV as first-line respiratory support, and in subjects transitioned from NIV to invasive mechanical ventilation in COPD (A) and non-COPD (B) subjects over the study period.

\section{Mortality}

Time trend of mortality did not reach statistical significance in the whole population (OR $0.98,95 \%$ CI $0.950-$ $1.010, P=.23)$, whereas SAPS II significantly increased, and duration of MV and lengths of ICU stay significantly decreased (Fig. 3). Time trend of mortality did not reach statistical significance in any of the chronic respiratory diseases categorized in our study.

Comparisons between subjects who died in the ICU and survivors are listed in Table 2, and variables found independently associated with ICU mortality after logistic regression analysis are shown in Table 3. Among the sub- 

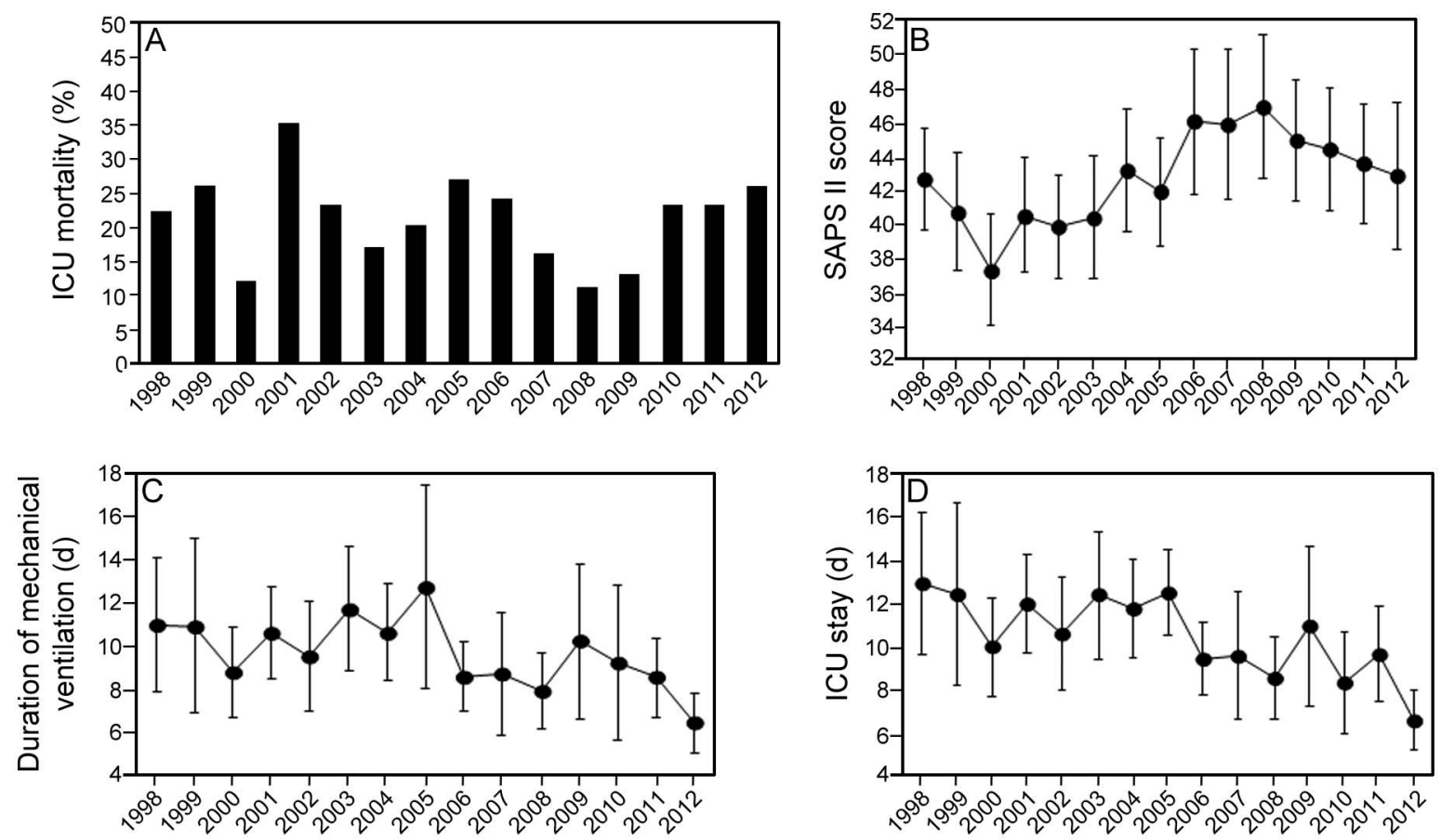

Fig. 3. Trends in mortality rates, Simplified Acute Physiologic Scores (SAPS) II, durations of mechanical ventilation, and lengths of ICU stay over the study period.

jects with ILD who received IMV, 2 subjects of 37 with IPF (5\%) and 13 subjects of 73 with non-IPF ILD (18\%) survived ( $P=.13$ after comparison). ILD was independently associated with mortality. When IPF and non-IPF ILD were distinguished in the adjusted prognostic analysis, both remained independently associated with mortality (IPF, OR $=30.3,95 \%$ CI 8.69-110, $P<.001$, and ILD non-IPF, OR $=7.46,95 \%$ CI 3.61-15.38, $P<.001$ ). No other chronic respiratory disease was found to be associated with mortality. In COPD and non-COPD subjects, mortality was significantly higher in subjects who failed NIV and lower in subjects treated with NIV only as compared with those treated with IMV (Table 4).

\section{Discussion}

In the present study, we have evaluated a real-life trend in use of NIV and or IMV in subjects with chronic respiratory disease and ARF. Surveys show that, in France, NIV is increasingly used in patients having acute or chronic respiratory failure ${ }^{17,18}$ with benefits. ${ }^{16}$ However, few data were provided regarding the underlying respiratory diseases involved. COPD subjects represent $50 \%$ of our study population, and, as others have, ${ }^{14,15}$ we report a significant increase in NIV use in these subjects, and a significant increase in the proportion of subjects initially treated with NIV. NIV use in patients with a COPD exacerbation has already been associated with a lower risk of nosocomial infections. ${ }^{23}$ For subjects without COPD and admitted for ARF, trends differed from the ones noted in COPD subjects. Over the study period, the proportion of subjects treated with NIV only did not significantly increase with time in subjects with respiratory disease other than COPD, whereas NIV was used more frequently as first-line treatment in obese subjects. To our knowledge, trends in NIV use had not been previously assessed over a period of several years in patients with bronchiectasis, restrictive disease, or ILD and compared with COPD patients.

Although bronchiectasis is a disease recognized with increasing frequency ${ }^{24}$ and associated with a poorer prognosis in subjects with moderate to severe COPD, ${ }^{25}$ we found that the number of subjects admitted to the ICU for respiratory failure and severe bronchiectasis has tended to diminish in the last decade. The significant increase during the study period in proportions of subjects with obesity was expected. In France, as in other developed countries, the proportions of obese subjects admitted to the ICU have increased over the last $20 \mathrm{y} .{ }^{26}$

In our ICU, progress in the management of ARF with NIV was not similar in COPD and non-COPD subjects over the period. Our results do not suggest that NIV is not useful in non-COPD patients but that its efficacy varies according to the underlying respiratory disease involved. As found in our study, previous studies have reported that NIV is feasible in subjects with bronchiectasis ${ }^{7}$ or chronic restrictive disease, ${ }^{10}$ but our results suggest that only a 
Table 2. Univariate Analysis for Death in the ICU

\begin{tabular}{|c|c|c|c|}
\hline \multirow[b]{2}{*}{ Variables on Admission } & \multicolumn{2}{|c|}{ Mortality in the ICU } & \multirow[b]{2}{*}{$P$} \\
\hline & $\begin{array}{c}\text { Alive } \\
(n=867)\end{array}$ & $\begin{array}{c}\text { Dead } \\
(n=246)\end{array}$ & \\
\hline COPD, $n(\%)$ & $477(55)$ & $88(36)$ & $<.001$ \\
\hline Bilateral bronchiectasis, $n(\%)$ & $88(10)$ & $25(10)$ & .99 \\
\hline Obesity $(\mathrm{BMI}>30), n(\%)$ & $155(18)$ & $14(6)$ & $<.001$ \\
\hline Diffuse interstitial pneumonia, $n(\%)$ & $34(4)$ & $97(39)$ & $<.001$ \\
\hline Restrictive disease, $n(\%)$ & $93(11)$ & $20(8)$ & .23 \\
\hline Asthma, $n(\%)$ & $20(2)$ & $2(1)$ & .22 \\
\hline Male gender, $n(\%)$ & $502(58)$ & $184(75)$ & $<.001$ \\
\hline SAPS II points (mean \pm SD) & $39 \pm 13$ & $53 \pm 19$ & $<.001$ \\
\hline Age, y $($ mean $\pm S D)$ & $67 \pm 12$ & $67 \pm 13$ & .80 \\
\hline $\begin{array}{l}\mathrm{P}_{\mathrm{aCO}_{2}}>50 \mathrm{~mm} \mathrm{Hg} \text { before ventilation, } \\
n(\%)\end{array}$ & $708(82)$ & $127(52)$ & $<.001$ \\
\hline $\begin{array}{l}\text { Obstructive sleep apnea syndrome, } \\
n(\%)\end{array}$ & $79(9)$ & $11(7)$ & .01 \\
\hline Prior oxygen therapy, $n(\%)$ & $166(19)$ & $58(24)$ & .13 \\
\hline $\begin{array}{l}\text { Lung and/or upper airway cancer, } \\
\qquad n(\%)\end{array}$ & $24(3)$ & $33(13)$ & $<.001$ \\
\hline $\begin{array}{l}\text { Chronic heart disease with treatment, } \\
n(\%)\end{array}$ & $559(64)$ & $152(62)$ & .44 \\
\hline $\begin{array}{l}\text { Infection and/or pneumothorax and or } \\
\text { pulmonary embolism, } n(\%)\end{array}$ & $281(32)$ & $104(42)$ & .00 \\
\hline Steroids $>1 \mathrm{mg} / \mathrm{kg} / \mathrm{d}, n(\%)$ & $458(53)$ & $198(80)$ & $<.001$ \\
\hline Initially on NIV, $n(\%)$ & $557(64)$ & $104(42)$ & $<.001$ \\
\hline NIV failure, $n(\%)$ & $143(16)$ & $95(39)$ & $<.001$ \\
\hline $\mathrm{IMV}, n(\%)$ & $453(52)$ & $237(96)$ & $<.001$ \\
\hline $\begin{array}{l}\text { BMI }=\text { body mass index } \\
\text { SAPS = Simplified Acute Physiologic Score } \\
\text { NIV = noninvasive ventilation } \\
\text { IMV = invasive mechanical ventilation }\end{array}$ & & & \\
\hline
\end{tabular}

Table 3. Variables Independently Associated With Mortality in the ICU

\begin{tabular}{lccc}
\hline \hline \multicolumn{1}{c}{ Variable } & OR & $95 \%$ CI & $P$ \\
\hline Diffuse ILD & 10.63 & $5.43-20.83$ & $<.001$ \\
Lung and/or upper airway cancer & 3.64 & $1.73-7.69$ & $<.001$ \\
Male gender & 1.99 & $1.31-3.04$ & .001 \\
SAPS II & 1.045 & $1.033-1.058$ & $<.001$ \\
$\mathrm{P}_{\mathrm{aCO}_{2}}>50 \mathrm{~mm}$ Hg before ventilation & 0.63 & $0.47-0.99$ & .04 \\
$\mathrm{NIV} \mathrm{failure}$ & 2.05 & $1.36-3.11$ & $<.001$ \\
$\mathrm{IMV}$ & 10.49 & $4.88-22.56$ & $<.001$ \\
& & & \\
\hline OR = odds ratio & & & \\
ILD, interstitial lung disease & & & \\
SAPS, Simplified Acute Physiologic Score & & & \\
NIV, noninvasive ventilation & & & \\
IMV, invasive mechanical ventilation & & & \\
&
\end{tabular}

third of these subjects can be successfully treated with NIV. On the other hand, our result suggest that, for obese subjects, the same success rate can be expected with NIV or even slightly higher than that obtained for COPD sub- jects. This last result is in accordance with the results of the study published by Carrillo et al, ${ }^{11}$ who demonstrated that subjects with obesity hypoventilation syndrome could be treated with NIV during an episode of acute hypercapnic respiratory failure with similar efficacy as for subjects with COPD. A major finding is that the proportion of patients with diffuse ILD successfully treated with NIV remained very low. We found that NIV was of little benefit in the management of subjects with ARF on ILD.

Like Chandra et al, ${ }^{14}$ we found that NIV failure was an independent factor of poor prognosis in the COPD subjects. We found that this was also true in non-COPD subjects. From 1998 to 2012, mortality rate did not decrease. However, SAPS II scores increased significantly during the study period, whereas durations of MV and lengths in ICU stay decreased significantly (Fig. 2). These results may be explained by a lack of power to detect a significant difference in ICU mortality.

The clinical impact of leak compensation during NIV remains unclear. After comparison, we did not observe a significant reduction in the rate of subjects transitioned from NIV to IMV with the use of ventilators able to compensate for air leaks, ${ }^{27}$ but the mean SAPS II in subjects initially treated with NIV was significantly higher in subjects with ventilators that were able to compensate for air leaks than in those during the previous period $(39 \pm 13$ vs $36 \pm 12$, respectively, $P=.006$ ). We found also that the proportion of COPD subjects who failed NIV did not decrease significantly with time, but SAPS II scores increased significantly over the study period. Perhaps our increasing experience with NIV allowed us to maintain the proportion of subjects successfully treated despite an increase in the severity of illness. In the present study, management of MV did not appear to have been influenced by the age of subjects.

The study has some limitations. First, it is a singlecenter study, consequently a high center effect for the analysis can be suspected. Second, it was not a randomized controlled study. The criteria for ICU admission were not standardized, and intubation decision was not controlled. The beliefs regarding efficacy of NIV may have differed among physicians when the chronic underlying respiratory disease involved was not COPD. Nevertheless, in our opinion, this study presented several strengths, including the large number of subjects with ARF and chronic respiratory disease other than COPD with outcomes assessed in the same time as the studies of a large population of COPD subjects and over a long period.

\section{Conclusions}

Our study depicts trends in the use of NIV in subjects with ARF and chronic respiratory diseases over the period 1998-2012, which differed whether this treatment was 
Table 4. Mortality Rates Compared in Subjects Who Failed NIV or Not or Were Treated by NIV Only During Their ICU Stay and According to Underlying Chronic Respiratory Disease

\begin{tabular}{|c|c|c|c|c|c|c|}
\hline \multirow{2}{*}{ Chronic Respiratory Disease } & \multicolumn{3}{|c|}{ Subjects Who Failed NIV } & \multicolumn{3}{|c|}{ Treated by NIV Only } \\
\hline & Alive & Dead & $P$ & Alive & Dead & $P$ \\
\hline COPD, $n(\%)$ & $80 / 480(17)$ & $23 / 88(26)$ & .03 & $227 / 480(47)$ & $6 / 88(7)$ & $<.001$ \\
\hline Bilateral bronchiectasis, $n(\%)$ & $14 / 88(16)$ & $14 / 25(56)$ & $<.001$ & $4 / 88(45)$ & $0 / 25(0)$ & $<.001$ \\
\hline Obesity (BMI > 30), $n(\%)$ & $52 / 274(19)$ & $16 / 30(53)$ & $<.001$ & $152 / 274(55)$ & $0 / 30(0)$ & $<.001$ \\
\hline Diffuse ILD, $n(\%)$ & $2 / 34(6)$ & $40 / 97(41)$ & $<.001$ & $19 / 34(56)$ & 2/97 (2) & $<.001$ \\
\hline Restrictive disease, $n(\%)$ & $21 / 93(23)$ & $11 / 20(55)$ & .003 & $40 / 93(43)$ & $1 / 20(5)$ & $<.001$ \\
\hline Asthma, $n(\%)$ & $1 / 20(5)$ & $0 / 2(0)$ & .99 & $0 / 20(0)$ & $0 / 2(0)$ & NA \\
\hline $\begin{array}{l}\text { NIV = noninvasive ventilation } \\
\text { BMI = body mass index } \\
\text { ILD = interstitial lung disease } \\
\text { NA = not available }\end{array}$ & & & & & & \\
\hline
\end{tabular}

applied in COPD or non-COPD subjects. The use of NIV increased throughout the study period in COPD but not in non-COPD subjects. However, in COPD and non-COPD subjects, NIV failure and IMV were associated with mortality in the ICU. Our results suggest that similar rates of success can be expected with NIV in the management of obese and COPD patients with ARF, while the efficacy of NIV appears restricted to a lower proportion of patients with bronchiectasis, restrictive disease, or ILD. Overall mortality of subjects ventilated for ARF on chronic respiratory disease did not decrease significantly, but severity of illness increased, and duration of mechanical ventilation and length of ICU stay decreased. Our results show that non-COPD patients should be distinguished from COPD patients when the efficacy of NIV is assessed in patients with ARF.

\section{REFERENCES}

1. British Thoracic Society Standards of Care Committee. Non-invasive ventilation in acute respiratory failure. Thorax 2002;57(3):192211

2. Bott J, Carroll MP, Conway JH, Keilty SE, Ward EM, Brown AM, et al. Randomised controlled trial of nasal ventilation in acute ventilatory failure due to chronic obstructive airways disease. Lancet 1993;341(8860):1555-1557.

3. Brochard L, Mancebo J, Wysocki M, Lofaso F, Conti G, Rauss A, et al. Noninvasive ventilation for acute exacerbations of chronic obstructive pulmonary disease. N Engl J Med 1995;333(13):817-822.

4. Mehta S, Hill NS. Noninvasive ventilation. Am J Respir Crit Care Med 2001;163(2):540-577.

5. Gupta P, Pendurthi MK, Modrykamien AM. Extended utilization of noninvasive ventilation for acute respiratory failure and its clinical outcomes. Respir Care 2013;58(5):778-784.

6. Dupont M, Gacouin A, Lena H, Lavoue S, Brinchault G, Delaval P, et al. Survival of patients with bronchiectasis after the first ICU stay for respiratory failure. Chest 2004;125(5):1815-1820.

7. Phua J, Ang YL, See KC, Mukhopadhyay A, Santiago EA, Dela Pena EG, Lim TK. Noninvasive and invasive ventilation in acute respiratory failure associated with bronchiectasis. Intensive Care Med 2010;36(4):638-647.

8. Fernandez-Perez ER, Yilmaz M, Jenad H, Daniels CE, Ryu JH, Hubmayr RD, Gajic. Ventilator settings and outcome of respiratory failure in chronic interstitial lung disease. Chest 2008;133(5):11131119.

9. Gaudry S, Vincent F, Rabbat A, Nunes H, Crestani B, Naccache JM, et al. Invasive mechanical ventilation in patients with fibrosing interstitial pneumonia. J Thorac Cardiovasc Surg 2013.

10. Robino C, Faisy C, Diehl JL, Rezgui N, Labrousse J, Guerot E. Effectiveness of non-invasive positive pressure ventilation differs between decompensated chronic restrictive and obstructive pulmonary disease patients. Intensive Care Med 2003;29(4):603-610.

11. Carrillo A, Ferrer M, Gonzalez-Diaz G, Lopez-Martinez A, Llamas $\mathrm{N}$, Alcazar M, et al. Noninvasive ventilation in acute hypercapnic respiratory failure caused by obesity hypoventilation syndrome and chronic obstructive pulmonary disease. Am J Respir Crit Care Med 2012;186(12):1279-1285.

12. Gupta D, Nath A, Agarwal R, Behera D. A prospective randomized controlled trial on the efficacy of noninvasive ventilation in severe acute asthma. Respir Care 2010;55(5):536-543.

13. Soroksky A, Stav D, Shpirer I. A pilot prospective, randomized, placebo-controlled trial of bilevel positive airway pressure in acute asthmatic attack. Chest 2003;123(4):1018-1025.

14. Chandra D, Stamm JA, Taylor B, Ramos RM, Satterwhite L, Krishnan JA, et al. Outcomes of noninvasive ventilation for acute exacerbations of chronic obstructive pulmonary disease in the United States, 1998-2008. Am J Respir Crit Care Med 2012;185(2):152159.

15. Funk GC, Bauer P, Burghuber OC, Fazekas A, Hartl S, Hochrieser $\mathrm{H}$, et al. Prevalence and prognosis of COPD in critically ill patients between 1998 and 2008. Eur Respir J 2013;41(4):792-799.

16. Schnell D, Timsit JF, Darmon M, Vesin A, Goldgran-Toledano D, Dumenil AS, et al. Noninvasive mechanical ventilation in acute respiratory failure: trends in use and outcomes. Intensive Care Med 2014;40(4):582-591.

17. Carlucci A, Richard JC, Wysocki M, Lepage E, Brochard L. Noninvasive versus conventional mechanical ventilation. An epidemiologic survey. Am J Respir Crit Care Med 2001;163(4):874-880.

18. Demoule A, Girou E, Richard JC, Taille S, Brochard L. Increased use of noninvasive ventilation in French intensive care units. Intensive Care Med 2006;32(11):1747-1755. 


\section{Ventilation in Acute Respiratory Failure}

19. American Thoracic Society. Standards for the diagnosis and care of patients with chronic obstructive pulmonary disease. Am J Respir Crit Care Med 1995;152(5 Pt 2):S77-121.

20. Travis WD, Costabel U, Hansell DM, King TE Jr, Lynch DA, Nicholson AG, et al. An official American Thoracic Society/European Respiratory Society statement: update of the international multidisciplinary classification of the idiopathic interstitial pneumonias. Am J Respir Crit Care Med 2013;188(6):733-748.

21. Lazarus SC. Clinical practice: emergency treatment of asthma. N Engl J Med 2010;363(8):755-764.

22. Gacouin A, Barbarot N, Camus C, Salomon S, Isslame S, Marque S, et al. Late-onset ventilator-associated pneumonia in nontrauma intensive care unit patients. Anesth Analg 2009;109(5):1584-1590.
23. Girou E, Schortgen F, Delclaux C, Brun-Buisson C, Blot F, Lefort Y, et al. Association of noninvasive ventilation with nosocomial infections and survival in critically ill patients. JAMA 2000;284(18): 2361-2367.

24. O'Donnell AE. Bronchiectasis. Chest 2008;134(4):815-823.

25. Martinez-Garcia MA, de la Rosa Carrillo D, Soler-Cataluna JJ, DonatSanz Y, Serra PC, Lerma MA, et al. Prognostic value of bronchiectasis in patients with moderate-to-severe chronic obstructive pulmonary disease. Am J Respir Crit Care Med 2013;187(8):823-831.

26. Mokhlesi B. Obesity hypoventilation syndrome: a state-of-the-art review. Respir Care 2010;55(10):1347-1362, discussion 1363-1345.

27. Scala R, Naldi M. Ventilators for noninvasive ventilation to treat acute respiratory failure. Respir Care 2008;53(8):1054-1080. 